\title{
Peroxidase Sensitive Amplifiable Probe for Molecular Magnetic Reso- nance Imaging of Pulmonary Inflammation
}

Aurora Rodríguez-Rodríguez, ${ }^{1}$ Sergey Shuvaev, ${ }^{1}$ Nicholas Rotile, ${ }^{1}$ Chloe M. Jones, ${ }^{1}$ Clemens K. Probst, ${ }^{2}$ Diego Dos Santos Ferreira, ${ }^{1}$ Katherine Graham-O'Regan, ${ }^{1}$ Eszter Boros, ${ }^{1}$ Rachel S. Knipe, ${ }^{2}$ Jason W. Griffith, ${ }^{2}$ Andrew M. Tager, ${ }^{2 \ddagger}$ Alexei Bogdanov $\mathrm{Jr}^{3}{ }^{3}$ and Peter Caravan ${ }^{1 *}$

${ }^{1}$ The Institute for Innovation in Imaging and the A. A. Martinos Center for Biomedical Imaging, Massachusetts General Hospital, Harvard Medical School, Charlestown, MA, United States, ${ }^{2}$ Division of Pulmonary and Critical Care Medicine and the Center for Immunology and Inflammatory Diseases, Massachusetts General Hospital, Boston, MA, United States, ${ }^{3}$ Department of Radiology, University of Massachusetts Medical School, Worcester, MA, United States

\section{TABLE OF CONTENTS}

I. MR IMAGING TO SEGMENT THE LUNG PARENCHYMA 2

II. HISTOLOGICAL AND BIOCHEMICAL CHARACTERIZATION OF THE MODEL 2

III. DYNAMIC MRI SHOWING BIODISTRIBUTION OF GD-5-HT-DOTAGA 3

IV. KINETIC INERTNESS 3

V. BIODISTRIBUTION 6

$\begin{array}{ll}\text { VI. } & \text { CHROMATOGRAPHY METHODS }\end{array}$

$\begin{array}{llr}\text { VII. } & \text { REFERENCES } & 8\end{array}$ 
In order to segment the large vessels and airways, the baseline RARE image and the post-Gd 3D FLASH images were used. The RARE sequence is a black blood sequence that shows the myocardium, liver, and large airways against a black background. The enhanced regions on the post Gd 3D FLASH image shows large blood vessels and the heart. These images were used to create regions of interest (ROIs) of the lung tissue, that were then copied onto the UTE images. The UTE images were used for the quantification of CNR.

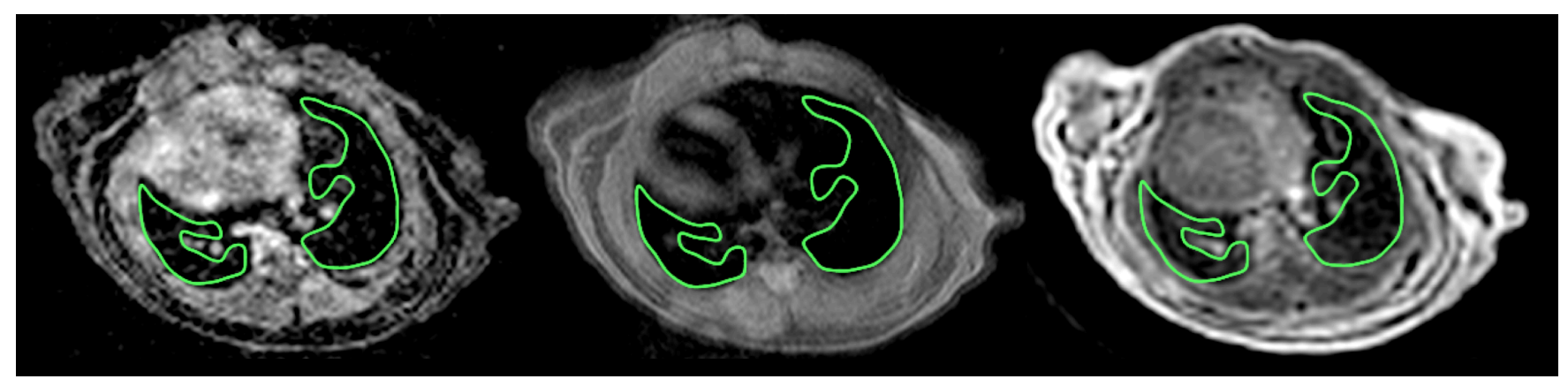

Figure S1. Example axial MR images with a 3D FLASH sequence post probe (left), the RARE sequence (middle), and the UTE sequence (right). Regions of interest defining the lungs in this slice are drawn in green.

\section{HISTOLOGICAL AND BIOCHEMICAL CHARACTERIZATION OF THE MODEL}

Sections of lung tissue were fixed in formalin, embedded in paraffin and stained with hematoxylin and eosin (H\&E) and with Masson's Trichrome. The left lung from cohorts of bleomycin injured or naïve mice were analyzed for hydroxyproline using a previously reported HPLC method. ${ }^{1}$
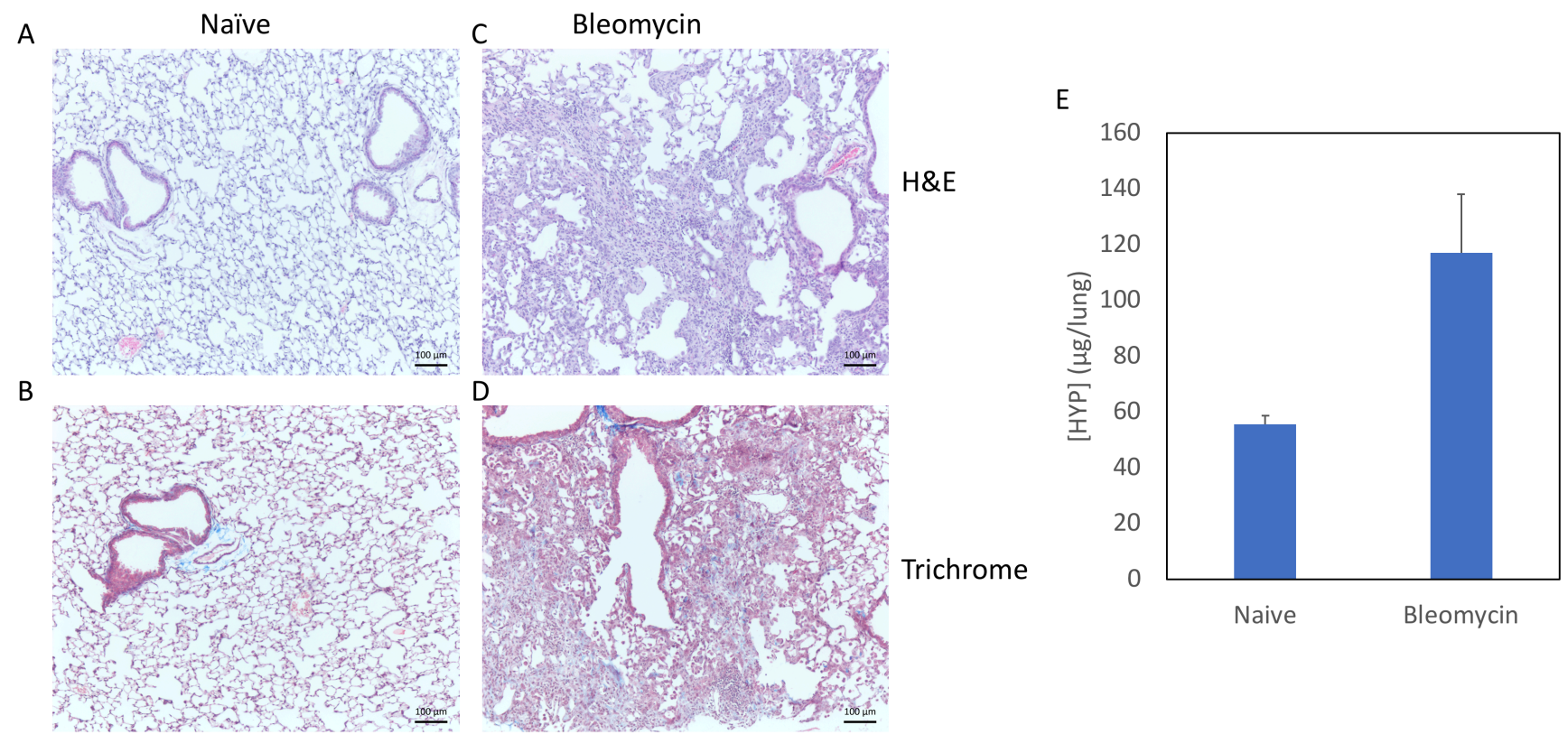

Figure S2. A-D) Histology of lung sections from naïve (A, B) and bleomycin injured mice (C, D, 21 days post bleomycin exposure) stained with $\operatorname{H\& E}(\mathrm{A}, \mathrm{C})$ or Trichrome $(\mathrm{B}, \mathrm{D})$. In contrast to the lungs of naïve mice, the bleomycin injured lung shows increased cellular density and presence of inflammatory cells on H\&E while on Trichrome fibrosis is apparent by areas of tissue stained in blue. E) Quantification of hydroxyproline (HYP) in the left lung of naïve and bleomycin injured mice, showing 2-fold higher concentration of this biochemical marker of fibrosis, $\mathrm{p}<0.01$. 


\section{DYNAMIC MRI SHOWING BIODISTRIBUTION OF GD-5-HT-DOTAGA}

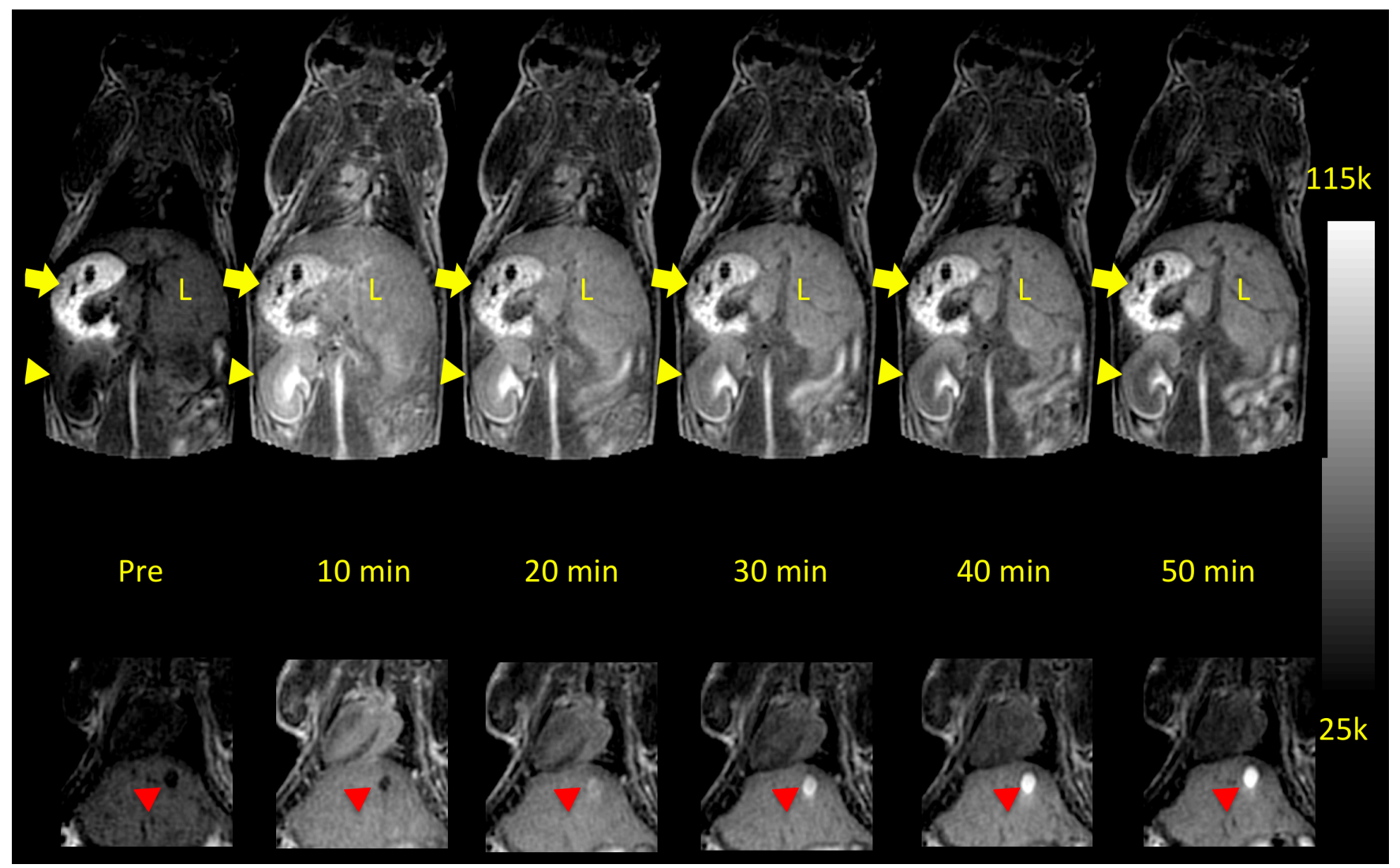

Figure S3. Time dependent coronal $\mathrm{T}_{1}$-weighted UTE images of a naïve mouse injected with Gd-5-HT-DOTAGA acquired before and at 5 time points after injection. The top panel shows a slice that contains the liver (L) and kidneys (yellow arrowhead); the stomach (thick arrow) is bright both pre- and post-injection. After probe injection all the tissues enhance. The kidney is immediately enhanced and signal decreases with time. Similarly, the liver is enhanced and this decreases with time. The rate of blood signal enhancement decay is faster than that of the liver such that contrast between the liver and large vessels is apparent from 30-50 min. The bottom panel shows a different slice containing the liver, heart, and gall bladder (red arrowhead). The signal in the ventricles of the heart is highest at 10 minutes post injection and then steadily clears. The signal in the gall bladder steadily increases with time indicating clearance from the liver and into the bile.

\section{KINETIC INERTNESS}

In order to test kinetic stability of commercially available gadolinium-based contrast agents, all complexes $(\sim 20$ $\mathrm{mM}$ ) were incubated in citrate buffer $(0.1 \mathrm{M}, \mathrm{pH} \sim 3)$ with an excess of MS-325 ligand (4 equivalents) added at elevated temperature $\left(52^{\circ} \mathrm{C}\right)$. Concentrations of MS-325 ligand and tested complexes were determined by UV-Vis spectroscopy at $\lambda=220 \mathrm{~nm}$. By comparing the absorbance intensity with a calibration curve generated by measuring a series of MS-325 solutions at different concentrations (exact concentrations were determined by measuring Gd content with ICP-MS). The samples were vigorously shaken and incubated at $52{ }^{\circ} \mathrm{C}$ in an oven (LAB-LINE INSTRUMENTS, Inc., No. 120 Incubator). $100 \mu \mathrm{L}$ aliquots were taken for HPLC analysis after 1, 2, 3, and 4 days. HPLC analysis was performed using ultra-aqueous C18 column $(5 \mu \mathrm{m}, 250 \mathrm{x} 4.6 \mathrm{~mm}$, RESTEK $), \mathrm{T}_{\text {of the column }}=40.0$ ${ }^{\circ} \mathrm{C}, 3 \mu \mathrm{L}$ of injection volume, $\lambda_{\text {detection }}=220 \mathrm{~nm}$, flow $=0.7 \mathrm{~mL} / \mathrm{min}$ ), gradient method: 


\begin{tabular}{|l|l|l|}
\hline Time (min) & A (\%) & B (\%) \\
\hline 0.00 & 60.0 & 40.0 \\
\hline 15.00 & 60.0 & 40.0 \\
\hline 19.00 & 5.0 & 95.0 \\
\hline 21.00 & 5.0 & 95.0 \\
\hline 23.00 & 60.0 & 40.0 \\
\hline 25.00 & 60.0 & 40.0 \\
\hline
\end{tabular}

Mobile phase A was a mixture of ammonium phosphate $(100 \mathrm{mM})$ and $\mathrm{Na}_{2} \mathrm{H}_{2}$ EDTA $(200 \mu \mathrm{M})$. Mobile phase B was a mixture of acetonitrile (60\%) and mobile phase A (40\%). This method gives a retention time for MS-325 ligand of $10.1 \mathrm{~min}$ and for MS-325 gadolinium complex a retention time of 12.5 and $13.5 \mathrm{~min}$ that corresponds to the two interconvertible diastereomers present in solution (Fig. S4): ${ }^{2}$

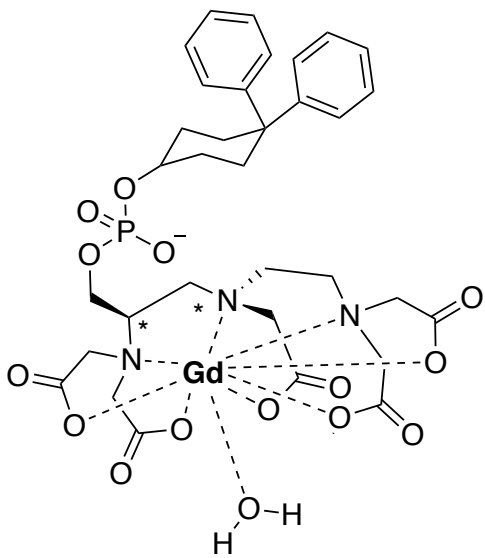

$(2 R, 4 S)$

Isomer A

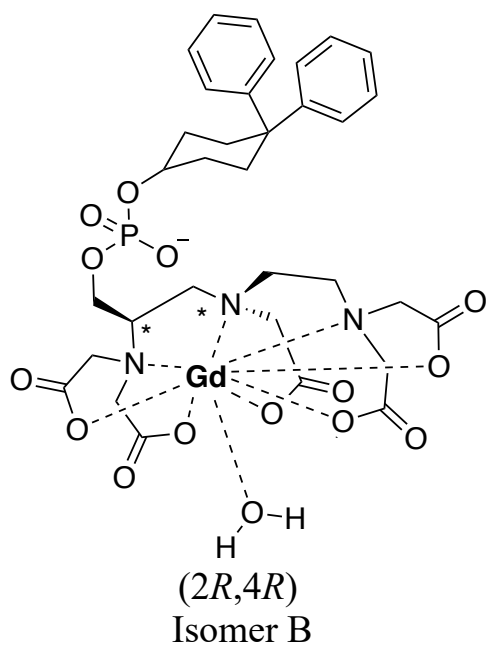

Isomer B

Figure S4. Isomerization equilibrium of MS-325 in solution (charges are omitted for simplicity).

Plots showing the $\%$ of each chelate converted to its ligand are shown in Figure S5. 


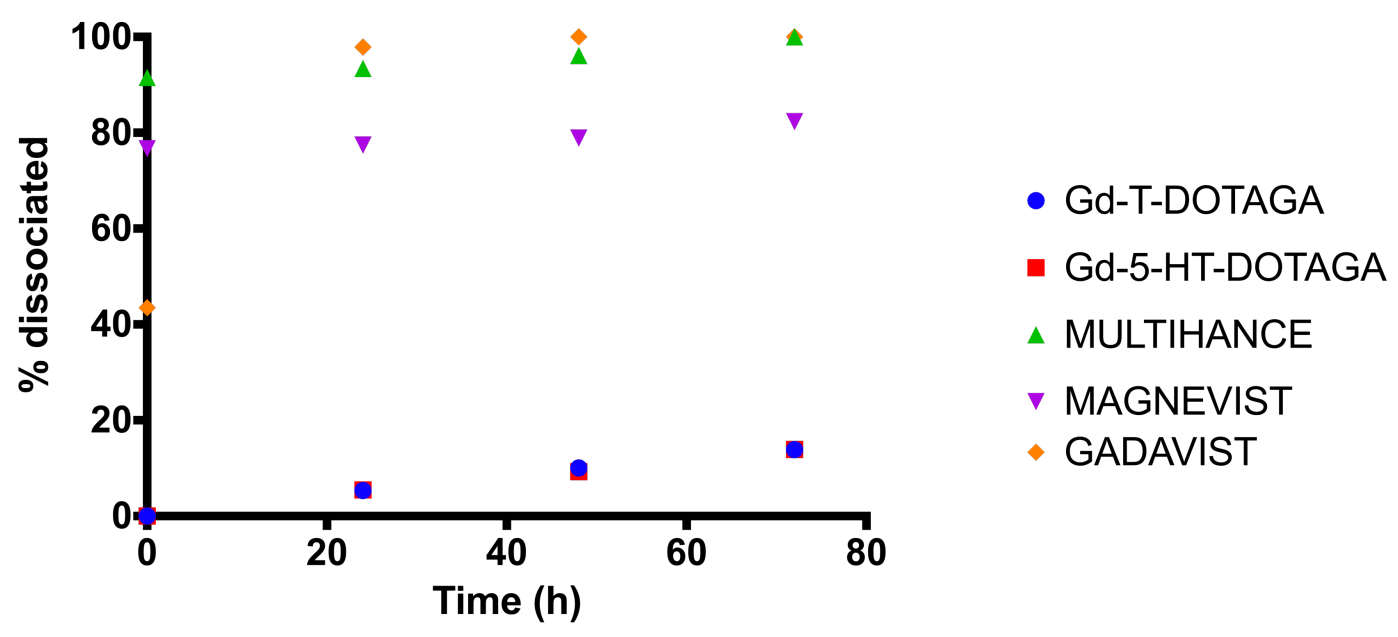

Figure S5. Dechelation of the gadolinium complexes at $\mathrm{pH} 3$ and $52{ }^{\circ} \mathrm{C}$ in the presence of $10 \mathrm{mM}$ citrate. 


\section{BIODISTRIBUTION}

Biodistribution was assessed by measuring the amount of $\mathrm{Gd}$ in each tissue at the end of the imaging study with the results shown in Figure S6.

\section{Naïve}

Gd-5-HT-DOTAGA

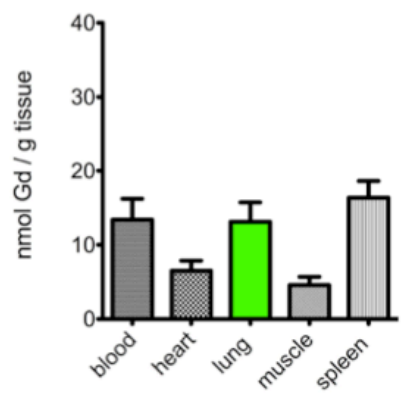

Naïve

Gd-T-DOTAGA

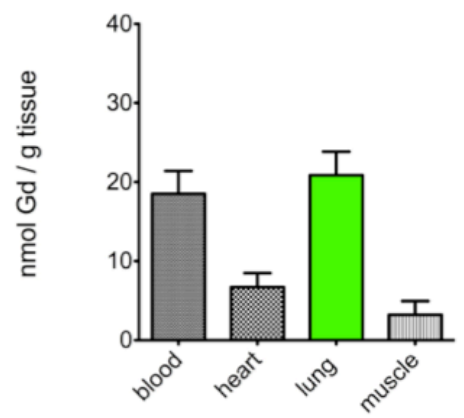

\section{Bleo}

Gd-5-HT-DOTAGA

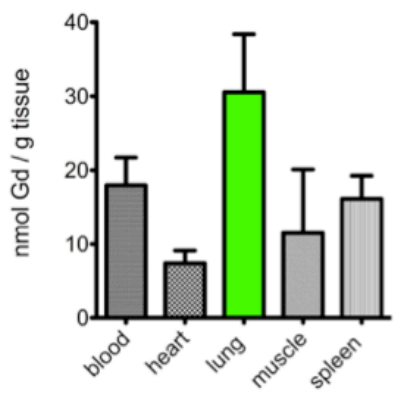

Bleo

Gd-T-DOTAGA

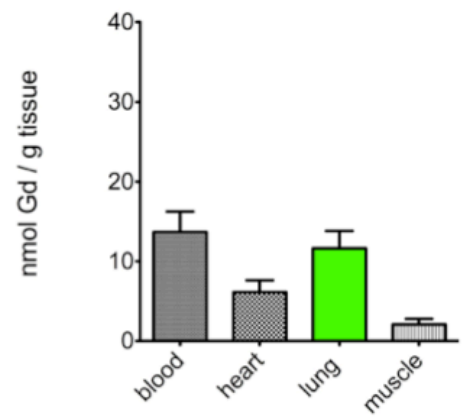

Figure S6. Concentration of gadolinium in blood, heart, lung and muscle in bleomycin treated and control animals with administered Gd-5-HT-DOTAGA or Gd-T-DOTAGA 


\section{CHROMATOGRAPHY METHODS}

\section{LC-MS METHODS}

Flow $=0.7 \mathrm{~mL} / \mathrm{min}$

Column $=$ Luna $^{\circledR} 5 \mu \mathrm{m} \mathrm{C18(2)} 100 \AA$, LC Column $100 \times 2 \mathrm{~mm}$

$\lambda_{1}=220 \mathrm{~nm}, \lambda_{2}=254 \mathrm{~nm}, \lambda_{3}=280 \mathrm{~nm}$

Method A:

\begin{tabular}{|l|l|l|}
\hline Time (min:s) & $\mathrm{H}_{2} \mathrm{O}(+0.1 \%$ Formic Acid $)$ & $\mathrm{CH}_{3} \mathrm{CN}(+0.1 \%$ Formic Acid $)$ \\
\hline $0: 00$ & 95 & 5 \\
\hline $6: 00$ & 5 & 95 \\
\hline $7: 50$ & 5 & 95 \\
\hline $8: 00$ & 95 & 5 \\
\hline $10: 00$ & 95 & 5 \\
\hline
\end{tabular}

Method B:

\begin{tabular}{|l|l|l|}
\hline Time (min:s) & $\mathrm{H}_{2} \mathrm{O}(+0.1 \%$ Formic Acid $)$ & $\mathrm{CH}_{3} \mathrm{CN}(+0.1 \%$ Formic Acid $)$ \\
\hline $0: 00$ & 95 & 5 \\
\hline $3: 00$ & 5 & 95 \\
\hline $4: 50$ & 5 & 95 \\
\hline $5: 00$ & 95 & 5 \\
\hline $7: 00$ & 95 & 5 \\
\hline
\end{tabular}

\section{PURIFICATION BY COMBIFLASH}

CombiFlash TELEDYNE ISCO (C18 Gold Columns)

Method C:

\begin{tabular}{|l|ll|l|}
\hline Column Volumes $(\mathrm{CV})$ & $\begin{array}{l}\mathrm{H}_{2} \mathrm{O} \quad(+0.1 \% \\
\text { Acid })\end{array}$ & Trifluoroacetic & $\begin{array}{l}\mathrm{CH}_{3} \mathrm{CN} \quad(+0.1 \% \text { Trifluoroacetic } \\
\text { Acid })\end{array}$ \\
\hline 0.0 & 95.0 & 5.0 \\
\hline 3.2 & 95.0 & 5.0 & \\
\hline 9.2 & 60.4 & 39.6 & \\
\hline 6.7 & 60.4 & 39.6 & \\
\hline 5.0 & 0.0 & 100.0 & \\
\hline 2.0 & 0.0 & 100.0 & \\
\hline 1.0 & 95.0 & 5.0 & \\
\hline 3.0 & 95.0 & 5.0 & \\
\hline
\end{tabular}

$\lambda_{1}=220 \mathrm{~nm}, \lambda_{2}=254 \mathrm{~nm}$

Method D:

\begin{tabular}{|l|l|l|}
\hline Column Volumes $(\mathrm{CV})$ & $\mathrm{H}_{2} \mathrm{O}(+0.1 \%$ Formic Acid $)$ & $\mathrm{CH}_{3} \mathrm{CN}(+0.1 \%$ Formic Acid $)$ \\
\hline 0.0 & 95.0 & 5.0 \\
\hline 3.0 & 95.0 & 5.0 \\
\hline 7.5 & 90.6 & 9.4 \\
\hline 2.0 & 90.6 & 9.4 \\
\hline 7.0 & 88.0 & 12.0 \\
\hline 0.7 & 85.5 & 14.5 \\
\hline 1.3 & 70.2 & 29.8 \\
\hline 1.2 & 26.4 & 73.6 \\
\hline 0.8 & 0.0 & 100.0 \\
\hline 3.0 & 0.0 & 100.0 \\
\hline 1.0 & 95.0 & 5.0 \\
\hline 3.0 & 95.0 & 5.0 \\
\hline
\end{tabular}

$\lambda_{1}=220 \mathrm{~nm}, \lambda_{2}=254 \mathrm{~nm}$ 


\section{REFERENCES}

1. Hutson PR, Crawford ME, Sorkness RL. Liquid chromatographic determination of hydroxyproline in tissue samples. J Chromatogr B Analyt Technol Biomed Life Sci 2003, 791, 427-430

2. Caravan, P.; Parigi, G.; Chasse, J. M.; Cloutier, N. J.; Ellison, J. J.; Lauffer, R. B.; Luchinat, C.; McDermid, S. A.; Spiller, M.; McMurry, T. J., Albumin binding, relaxivity, and water exchange kinetics of the diastereoisomers of MS-325, a gadolinium(III)-based magnetic resonance angiography contrast agent. Inorg Chem 2007, 46 (16), $6632-9$. 